\title{
Linguistic models of social and political communication in the online-space: cognitive and pragmatic aspect
}

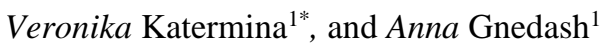 \\ ${ }^{1}$ Kuban State University, ul. Stavropolskaya 149, 350040, Krasnodar, Russian Federation
}

\begin{abstract}
The socio-political context of the «post-truth» era, conditioned by the digitalization of all spheres of life, transforms the network content, which forms the basis of network discourses and is the main source of information for the network society. As a result, network content is not simply determined by the categorical concepts of «fact» - «myth», but is completely transformed into the conceptual-categorical apparatus «fact»«alternative fact», which is essentially informational speculation and leads to the development of destructive socio-political practices and distribution of fake online content. Based on a comprehensive analysis of network data (a methodology developed by the authors that combines theories and methodologies of several areas of scientific knowledge), linguistic models of social and political communication in the online-space were identified and described («Ali Juppe» in France, «Pizzagate» in the USA, «Migrantskidnappers» in India and Pakistan); the result of consumption of new linguo-pragmatic patterns («Allan Juppe - an accomplice of Islamic extremists»; «Don't vote for Clinton, Vote for Trump» and the side pattern «Save children from pedophiles»; «Pakistani migrants pose a threat») by users of the online-space in the specified countries was investigated; the results of the models' actions are given and the offline result of the consumption of these patterns is described. The research develops a new direction of linguistic science - network linguistics; consideration of new network models of communication (cognitive stereotypes and linguopragmatic patterns) in the online-space is the main genuine identifier of the discourse varieties formed offline that determine the further behavior (constructive and / or destructive) of the user both online and offline.
\end{abstract}

\section{Introduction}

The Internet which is a multimodal, multicultural and multilingual platform for discourse interactions is the main source of obtaining and disseminating information (diverse in content and pragmatic potential) both for ordinary users and for social and traditional media. Currently $51.2 \%$ of all websites and web pages still use English as their primary language, with the regions with the highest number of Internet users being Asia (48.7\%),

\footnotetext{
* Corresponding author: veronika.katermina@yandex.ru
} 
Europe (17.0\%) and Africa (10.9\%) [1]. Thus, the linguo-cognitive and linguodiscursive aspects of discursive interactions in the online-space are becoming increasingly important.

Every second a colossal amount of network data is produced in the online-space, the impact potential of which is difficult to assess or predict. Digital technologies form a new culture of interaction - collaboration, exchange of information and resources, interactivity and multimedia - that allow the formation of a new type of content in terms of form, content, linguocultural characteristics and implicit meanings [2]. The collective consciousness due to the functioning of network communities in the "filter bubble» is becoming the dominant form of «thought» in the modern world: individuality ceases to be a virtue. Divergence, dissent, a «do it yourself» approach and «independent investigation» are perceived as a destructive component of discursive interaction, as it leads to tragic consequences, threatens security and undermines trust in government, moral foundations which carries a destructive potential to influence the development of socio-political systems in the modern world.

The nature, models and format of presentation and consumption of information in a networked society have radically changed and there are social platforms, group chats in messengers, comments and likes to posts, videos, GIFs, memes, tweets [3]. Networked discursive interaction in the online-space has become fragmented (clip thinking), digressive, multimodal and multilinear [4].

The colossal array of network data generated by the discursive fields in the online-space does not allow instantaneous or timely tracking destructive changes in the socio-political sphere. The result is the registration of destructive practices of the influence of the discursive space on the development of socio-political systems after the fact.

\section{Problem Statement and Theoretical Approaches}

Socio-political online-space being a global discursive space from the point of view of the potential of the totality of discursive fields that form this space provides a connection between political subjects and is the sphere of their functioning. An important distinctive feature of the discourse space is the high potential for initiating transformations of sociopolitical systems through the production of complex, stable constructs - linguistic patterns that have a repetitive emotional component that has an effective impact on the recipient's imaginative thinking, his cognitive attitudes, including decision-making and conditioning high pragmatic potential and stable tonality of the discursive field that generates this pattern.

Network discourse arises when a certain reality phenomenon begins to be discussed, cited or changed because of the enrichment of opinions or thoughts of an individual. Online-space discursive fields appear due to the reaction to reality when some participants in the process of communication reach a «critical number» of users and thus a discursive «force field» can be formed. It may imply impacting the members in discursive interaction - their opinions, thoughts, assessments thus finally coming to a particular decision. The powerful influence of discursive fields on the organization of content consumption can serve as a solid manipulative base - political, ideological, psychological, cognitive attitudes are introduced into mass consciousness through the formation and functioning of a certain discursive field [5-8]. The «forceful nature» of online discursive fields is ensured by their functioning in the so-called «filter bubble» and by complex linguo-cognitive structures generated by the discursive field - innovative linguistic patterns.

Understanding the fundamental principles of the functioning of discursive fields as a sphere of functioning of network discourses enables us to identify triggers and determine the point of formation of a «critical number» of users leading to the formation of a certain discursive field; to define and describe a complex set of linguistic tools that ensure the 
purposeful formation of a certain linguistic pattern within the framework of the discursive field; typologize discursive fields depending on their constructive and / or destructive potential of influence on the development of socio-political systems; to influence the constructive and destructive vectors of the development of discursive fields in the onlinespace.

\section{Linguistic Models Of Social And Political Communication In The Online-Space: 3 case-studies}

Let us consider three examples of the formation of linguistic models of socio-political communication in the online-space formed as a result of the development of manipulative discursive fields and new linguistic patterns. The result of these communications in three different countries was the formation of mass and individual destructive socio-political actions. These models were obtained on the basis of a comprehensive analysis of network data and a methodology developed by the authors [9-11] combining the theory and methodology of several areas of scientific knowledge: network (data) analysis, deep text analysis, object-oriented programming method, linguistic discursive analysis, relational sociology, interpretation, content method, folksonomic analysis.

The first case: the «Ali Juppe» model and the linguo-pragmatic pattern «Allan Juppe an accomplice of Islamic extremists».

During the 2016-2017 election campaign in France, Alain Juppe, occupying the position of the mayor and being the candidate from the right-wing Republicans party for the primaries changed his decision because of the continuing "noise" in the information fields which reflected negatively his campaign.

This event was crucial for spreading information within the discursive field made by mass media about Alain Juppe's connection with radical Islamists' organizations. He was nicknamed" which became possible due to the viral and fake content and as a consequence it led to the destruction of his political career as a presidential candidate.

The discursive field "Ali Juppe - an accomplice of Islamic extremists" was created by mass media with the help of hashtags, play on words and allusions. The play on words and allusion was to replace the candidate's name - Alain - with one of the most common male names in Muslim countries - Ali. Allusion as an intertextually complicated nomination has a strictly defined nominative technique. Understanding intertextuality as the dependence of the generation or perception of a given text on the communicants' knowledge of other texts, we can talk about mediation - the degree of tension in the recipient's understanding of intertextual references which leads to additional textual shades and new semantic layers. As a result, the linguosemiotic unit \#allainjuppé was transformed into the unit \#alijuppé, which was used to mark all the materials defaming Alain Juppé posted in the online-space. This became the base which eventually formed the discursive field «Alain Juppe - an accomplice of Islamic extremists». Internet users who join this discursive field consuming the content produced by this field came to the conclusion that one of the candidates for the presidency of France - A. Juppe - is an accomplice of extremists. Thus, we are talking about the fact that the discursive field gave rise to the linguo-pragmatic pattern - «Do not vote for Alain Juppe» which resulted in a certain social action: the voters decided not to vote for him.

The second case: the «Pizzagate» model and the linguistic-pragmatic pattern «Don't vote for Clinton, Vote for Trump, since Clinton's supporters are engaged in discrediting activities» plus the side pattern «Save the children from pedophiles».

In 2016 one more discursive field was formed in the online- space - the so-called the Pizzagate discursive field. It was created during the election presidential campaign in the USA. This field contained the content that the influential supporters of H. Clinton were 
allegedly related to a secret organization carrying out violent acts against children. The basis of this content was a conspiracy theory based on excerpts from the email correspondence of John Podesta, who was the chief of staff of H. Clinton, and speculation that some of the words that regularly appear in Podesta's correspondence are code words meaning violence and child trafficking. The Pizzagate discursive field has embraced platforms such as 4chan, Twitter and Reddit. The scale of the discursive field was so global that it went beyond social platforms and embraced mainstream news sites - Godlike Productions, YourNewsWire, SubjectPolitics, Conservative Daily Post, The New York Times, which have a fairly high user trust rating.

The discursive field «Pizzagate» was created deliberately with the aim of discrediting presidential candidate $\mathrm{H}$. Clinton through the formation of the linguistic pragmatic pattern «Don't vote for Clinton, Vote for Trump, since Clinton's supporters are engaged in defamatory activities».

However, the formed pattern turned out to be multi-layered in terms of implications and modalities and in addition to the predicted and expected message not to vote for H. Clinton; it turned to morality and ethics and also motivated a social action to fight for the children's rights of children, the children who were subjects to violence. The creation of this linguistic discursive pattern led to the following event: a 28-year-old Edgar Maddison Welch from North Carolina went on a rampage and shot at Comet Ping Pong in 2016, on December 2016. He was perfectly sure that he was liberating the children being held as hostages. $\mathrm{He}$ told the police how exactly he was misled and why he crossed the whole country with a weapon: the reason for everything is the discursive field of «Pizzagate» in the online-space and the consumption of the collateral linguodiscursive pattern «Save children from pedophiles», which ultimately led him to private investigation (self-investigation) and armed lynching.

The third case: the Kidnapper Migrant model and the linguistic pragmatic pattern «Pakistani migrants / strangers on the streets of your cities are a threat».

The advertising agency Spectrum Y\&R in 2016 created a social video for the non-profit organization Roshni Helpline to prevent abduction and trafficking of children in Pakistan. The purpose of this video was to form the pattern «Watch your child!», the use of which would increase the level of responsibility of the parents. In the video, the kidnapping of a child from the city street was staged, filmed, in accordance with the director's intention, with an external surveillance camera (which gave special realism to what was happening). The video showed how easy it is to kidnap children from the streets of Pakistani cities. The social video ended with the kidnappers returning the child and unrolling a poster that said «It takes only a moment to kidnap a child from the streets of Karachi». Two years later, in the spring of 2018, the edited version of this social video (but without the instructive message to parents - «Watch your child!») instantly spread thanks to Internet technologies throughout India supplemented by rumors that migrants began to abduct children and this is a «live» filming of such an abduction. A discursive field of such a scale as «Pakistani immigrants in India kidnap children» was made. This alleged fact was justified. The reason for the creation of this field was proved too. As a result there appeared an edited fake video, which disseminating through the messenger popular in India and Pakistan WhatsApp and then regional media went viral instantly. The product of the functioning of this field was the linguo-pragmatic pattern «Pakistani migrants / strangers on the streets of your cities pose a threat», which is different from the one originally conceived by Spectrum $Y \& R$, and the mass consumption of which caused panic among the population, led to actions of social disobedience and loss of life by migrants. 


\section{Conclusion}

The result of the action of the «Ali Juppe» model and the consumption of the linguopragmatic pattern «Allan Juppe - an accomplice of Islamic extremists»:

- for the first time the image of a politician during the election campaign was completely ruined - the texts defaming the candidate created a discursive field where a linguistic pattern was formed; as a result it created a negative image of a politician due to undermined voters' trust.

The result of the «Pizzagate» model, the consumption of the linguo-pragmatic pattern «Don't vote for Clinton, Vote for Trump, since Clinton's supporters are engaged in discrediting activities» and the side pattern «Save children from pedophiles»:

- in the modern conditions of massive dissemination of disinformation - in the «Posttruth Era» - the phrase "self-investigation» reveals the essence of a radically new relationship between citizens, truth and social action. Millions of people, like Welch, abandon critical attitude to information sources being in the "filter bubble", apply the "do it yourself" approach while searching and validating information which created sudden and unpredictable social actions.

Outcome of the Kidnapper Migrant model and the consumption of the linguo-pragmatic pattern «Pakistani migrants / strangers on the streets of your cities pose a threat»:

- panic among the population, which led to actions of social disobedience and death of people by migrant communities.

These examples show how information and communication technologies transform social reality and pose new research questions to how exactly linguistic models (discursive fields and content contained in them) and the linguistic patterns they produce initiate a social action that affects development and transformation of socio-political systems of modern states.

The analysis of fake network content developed by the authors, identified and investigated models of socio-political communication in the online-space in the post-truth era makes it possible to develop ways to prevent the development of destructive social practices (individual - «self-investigation» and group - mass actions protest, activity of social movements) as a consequence of the influence and involvement of users / communities of users in a certain manipulative discursive field in the online-space, such as, for example, «Pizzagate» in the USA a fake political field formed in relation to a French politician and tragic events in India and the USA provoked by fake online content.

\section{Acknowledgments}

This work was supported by the Russian Foundation for Basic Research, grant No. 20-01200033

This paper was financially supported by the Russian Foundation for Basic Research, grant No. 20-012-22046.

\section{References}

1. Internet World Stats. Retrieved from: https://www.internetworldstats.com/\#links4 (2020)

2. The age of perplexity: rethinking the world we knew. New York: Penguin (2018) 
3. J. T. Feezell. Agenda Setting through Social Media: The Importance of Incidental News Exposure and Social Filtering in the Digital Era. In Political Research Quaterly, 71 (2), 482-494. https://doi.org/10.1177/1065912917744895 (2018)

4. N. A. Ryabchenko, O. P. Malysheva. Characteristics of modern political communication in the online-space. In Questions of cognitive linguistics, 3, 101-113 (2020)

5. S. González-Bailón, N.Wang. Networked discontent: The anatomy of protest campaigns in social media. In Social Networks, 44, 95-104. DOI: https://doi.org/10.1016/j.socnet.2015.07.003 (2016)

6. R.H. Jones, A. Chik, C. A. Hafner. Discourse and digital practices: Doing discourse analysis in the digital age. New York: Routledge (2015)

7. S. Bhatia, G. P. Goodwin, L. Walasek. Trait Associations for Hillary Clinton and Donald Trump in News Media. A Computational Analysis. In Social Psychological and Personality Science, 9 (2), 123-130. DOI: https://doi.org/10.1177/1948550617751584 (2018)

8. K. Jaidka, A. Zhou, Y. Lelkes. Brevity is the Soul of Twitter: The Constraint Affordance and Political Discussion. In Journal of Communication, 69 (4), 345-372. (2019)

9. V. V. Katermina, A. A. Gnedash. Formation of political content in online space: a structural-network and linguodiscursive analyses of modern social movements (as exemplified by “Women's March”). In Political Linguistics, 4 (70), 103-111. (2018)

10. N. A. Ryabchenko, V. V. Katermina, A. A. Gnedash, O. P. Malysheva. Political Content of Social Movements in the Online-Space of Modern States: Analysis Methodology and Research Practice. In South Russian Journ. of Social Sciences, 3, 139-162. (2018)

11. N. A. Ryabchenko, V. V. Katermina, A. A. Gnedash, B. G. Vulfovich. Regional Political Discourse: Theoretical Model, Methodology of Research and Practice of Managing Political Content in the Online-Space of the Russian Federation Subjects. In Political Linguistics, 5 (77), 114-131. DOI 10.26170/pl19-05-12 (2019) 